\title{
Does a waist-worn ActiGraph accelerometer quantify community ambulation in persons with multiple sclerosis?
}

\author{
Jacob J. Sosnoff, PhD; ${ }^{1-2^{*}}$ Michael J. Socie, MS; ${ }^{3}$ Morgan K. Boes, MS; ${ }^{2}$ Brian M. Sandroff, MS; ${ }^{1}$ Robert W. \\ Motl, PhD $^{1}$ \\ Departments of ${ }^{1}$ Kinesiology and Community Health, ${ }^{2}$ Bioengineering, and ${ }^{3}$ Mechanical Sciences and Engineering, \\ University of Illinois at Urbana-Champaign, Urbana, IL
}

\begin{abstract}
Accelerometry has been recognized as a method of objectively measuring community ambulation in persons with multiple sclerosis (MS). However, the assumption that walking itself serves as a major contributor to the accelerometer signal has yet to be tested. This study examined the assumption that community-based walking is a primary contributor to accelerometer output in MS. Ambulatory persons (5 males/17 females; 13 without aid/9 with aid) with MS wore a triaxial accelerometer (ActiGraph GT3X, Health One Technologies; Fort Walton Beach, Florida) as well as an IDEEA system (MiniSun, Inc; Fresno, Florida) over the course of a single day. Outcome measures for the accelerometer included movement counts/hour for the vertical, anterior-posterior, and mediolateral axes. Outcomes for the IDEEA system included percent time walking, sitting, and standing, as well as walking speed. Pearson product correlations ( $r$ ) were used to examine the associations between outcomes from the accelerometer and IDEEA system. Significant correlations were observed between percent walking time and movement counts/hour along the vertical $(r=0.84)$ and anterior-posterior $(r=0.69)$ axes. Significant correlations were further noted between movement counts/hour along the vertical axis and walking speed $(r=0.45)$ and self-report walking impairment $(r=-0.50)$ and disability $(r=-0.46)$. Such observations further support accelerometry as an objective marker of community ambulation in persons with MS.
\end{abstract}

Key words: accelerometry, activity, ambulation, community ambulation, free living, locomotion, mobility, multiple sclerosis, outcome measures, walking.

\section{INTRODUCTION}

The loss of walking is a common consequence of multiple sclerosis (MS). Nearly 85 percent of persons with MS identify walking problems as a primary limitation that affects functioning and activities of daily living [1-2]. By extension, the measurement of walking has become an important outcome in clinical research and practice in this population [3].

Accelerometry has been identified as an objective measure of community walking in neurological disorders, including MS [4-6]. This is important because most measures of walking in MS are performed in laboratory or clinical settings and suffer from poor ecological or realworld validity. Nevertheless, the application of accelerometry as an objective measure of community ambulation in MS rests on several tested and untested assumptions.

Abbreviations: $\mathrm{AP}=$ anterior-posterior, EDSS $=$ Expanded Disability Status Scale, ML = mediolateral, $\mathrm{MS}=$ multiple sclerosis, MSWS-12 = Multiple Sclerosis Walking Scale-12, $\mathrm{SD}=$ standard deviation.

*Address all correspondence to Jacob J. Sosnoff, PhD; University of Illinois at Urbana-Champaign, Department of Kinesiology and Community Health, 301 Freer Hall, 906 South Goodwin Ave, Urbana, IL 61801; 217-333-9472; fax: 217-244-7322. Email: jsosnoff@illinois.edu

http://dx.doi.org/10.1682/JRRD.2011.11.0218 
Existing data indicate that movement or activity counts from an accelerometer worn around the waist capture inter- and intraindividual variation in overground walking within a clinical setting [7], accelerometer movement or activity counts over a $7 \mathrm{~d}$ period are associated with spatiotemporal parameters of gait [8], and walking is a primary self-selected physical activity among persons with MS [9]. One of the most important untested assumptions is that community walking itself is a major contributor to the accelerometer signal in persons with MS. There are no extant data indicating that the accelerometry signal results predominantly from community walking in persons with MS. To that end, this investigation examined the association between community-based walking and movement (e.g., activity) counts recorded by a waistworn accelerometer in persons with MS.

\section{METHODS}

\section{Participants}

The sample comprised 22 ambulatory persons (5 males/17 females) with a definite diagnosis of MS consistent with Poser and/or McDonald criteria [10-12]. Demographic information is provided in Table 1. Participants ranged in age from 23 to $64 \mathrm{yr}$ with a mean of $46.9 \mathrm{yr}$ (standard deviation $[\mathrm{SD}]=11.7 \mathrm{yr}$ ). The average time since diagnosis was $11.0 \mathrm{yr}(\mathrm{SD}=6.9 \mathrm{yr})$. Nine $(41 \%$ of the sample) of the participants used a cane during testing as well as in everyday life. The sample had a range of Expanded Disability Status Scale (EDSS) scores between 0 and 6.0 (interquartile range $=2.5$; median $=3.0$ ).

\section{Procedures}

Upon arrival at the laboratory, participants provided demographic information and completed the self-reported EDSS [13-14] and the Multiple Sclerosis Walking Scale12 (MSWS-12) [15]. The participants were then outfitted with a waist-worn triaxial accelerometer (ActiGraph
GT3X, Health One Technologies; Fort Walton Beach, Florida) and an IDEEA system (MiniSun, Inc; Fresno, Florida). The GT3X accelerometer contains a solid-state, digital accelerometer that generates an electrical signal proportional to the force acting on it along three axes. The IDEEA system consists of 5 uniaxial accelerometers placed on the plantar surfaces of each foot, the anterior portions of each thigh, and centered on the sternum. Based on the activation pattern of the accelerometers, the accompanying software is capable of determining behaviors such as sitting, standing, and walking. The IDEEA system has evidence for its reliability and validity in both nondisabled and pathological populations [16-20]. Participants arrived at our laboratory early in the morning to accumulate a full day's wear time of the accelerometers. Once outfitted with both the triaxial accelerometer and the IDEEA system, participants continued with a normal daily routine. Participants were instructed not to deviate from normal daily activities. Participants returned to the laboratory in the evening and had the equipment removed.

\section{Data and Statistical Analysis}

Outcome measures for the accelerometer included activity counts/hour for the vertical, anterior-posterior (AP), and mediolateral (ML) axes. While step counts derived from an accelerometer are traditionally used to quantify physical activity levels, they only measure whether a step has taken place without providing information regarding the quality of the step. In contrast, activity counts took into account the binary event of a step as well as the quality/intensity of the step. Outcomes for the IDEEA system included percent time walking, sitting, and standing as well as walking speed (meters/minute). All analyses were completed using SPSS version 17.0 (IBM; Armonk, New York) and significance was noted at $p<0.05$. Means and SD were calculated for all outcome measures. Pearson product correlations $(r)$ were used to examine the association between activity counts

Table 1.

Demographics of 22 participants with multiple sclerosis.

\begin{tabular}{lcccc}
\hline \multicolumn{1}{c}{ Variable } & Mean & Standard Deviation & Minimum & Maximum \\
\hline Age (yr) & 46.9 & 11.7 & 23 & 64 \\
Yr-D $_{\mathrm{X}}$ & 11.0 & 6.9 & 1.0 & 23.0 \\
EDSS $_{\mathrm{SR}}$ (median IQR) & 3.0 & 2.5 & 1.0 & 6.0 \\
Assistive Device Usage (\%) & 41 & $\mathrm{NA}$ & $\mathrm{NA}$ & $\mathrm{NA}$ \\
EDSS $_{\mathrm{SR}}=$ self-report Expanded Disability Status Scale, IQR = interquartile range, NA = not applicable, Yr-D & years since diagnosis. \\
\hline \hline
\end{tabular}


and behavior (e.g., walking, standing, and sitting). Values are reported as mean \pm SD.

\section{RESULTS}

Wear times for the devices ranged from 6.0 to $10.1 \mathrm{~h}$ and average $7.6 \pm 1.6 \mathrm{~h}$. Mean activity counts/hour along the vertical, AP, and ML axes were 10,938 \pm 6,313, 15,803 \pm 6,583 , and $17,253 \pm 7,684$, respectively. Participants sat $61.3 \pm 16.9$ percent, stood $23.6 \pm 13.8$ percent, and walked $5.7 \pm 3.6$ percent of the time. Mean walking speed was $57.6 \pm 13.2 \mathrm{~m} / \mathrm{min}$. Mean self-perceived walking impairment was $40.3 \pm 26.5$ based on MSWS-12 scores.

As reported in Table 2, percent time spent walking was significantly correlated with activity counts along the vertical $(r=0.84)$ and AP $(r=0.69)$, but not ML $(r=0.40)$, axes. Percent sitting was significantly associated with activity counts along the AP $(r=-0.54)$ and ML $(r=-0.64)$, but not vertical ( $r=-0.39$ ), axes. Percent standing was significantly correlated with movement counts along the ML axis $(r=-0.63)$. Only movement counts along the vertical axis were significantly associated with walking speed $(r=0.45)$, self-reported EDSS scores $(r=-0.46)$, and MSWS-12 scores $(r=-0.50)$. The amount of walking and walking speed were further associated with self-reported EDSS scores ( $r=-0.51$ and -0.57 , respectively) and MSWS- 12 scores (both -0.49 ).

\section{DISCUSSION}

This investigation tested the assumption that a waistworn accelerometer captures community walking behav- ior in persons with MS. To that end, the primary novel results were that activity counts along the vertical axis were associated with time spent walking as well as walking speed, disability status, and self-reported walking impairment. Collectively, this further indicates that accelerometry provides an objective measure of community ambulation in MS.

Conceptually, the degree of walking impairment in MS depends on the interplay among pathological, physiological, personal, and environmental parameters [6]. Yet, researchers and clinicians routinely measure walking impairment using the $500 \mathrm{~m}$ walk of the EDSS and timed walk tests [21-24]. The primary limitation of those measures involves performance under controlled, static circumstances. Such conditions reflect the effect of pathological, physiological, and personal factors on ambulatory impairment but do not account for additive influence of community or environmental factors. Consequently, those measures fail to reliably capture impairments in community-based ambulation. By comparison, the results from the current study suggest that accelerometry can capture the amount and quality of walking (e.g., speed) in a real-world environment. When considering the results of this study along with previous research [4,6-7,9], substantial evidence exists supporting the application of commercially available, waist-worn accelerometers for measuring community-based ambulation in persons with MS.

The findings of this study extend research examining accelerometry as an objective marker of walking impairment. For instance, data indicate that a waist-worn accelerometer is sensitive to intra- and interindividual variation in

Table 2.

Correlation coefficients between accelerometer, motor behavior, and disability.

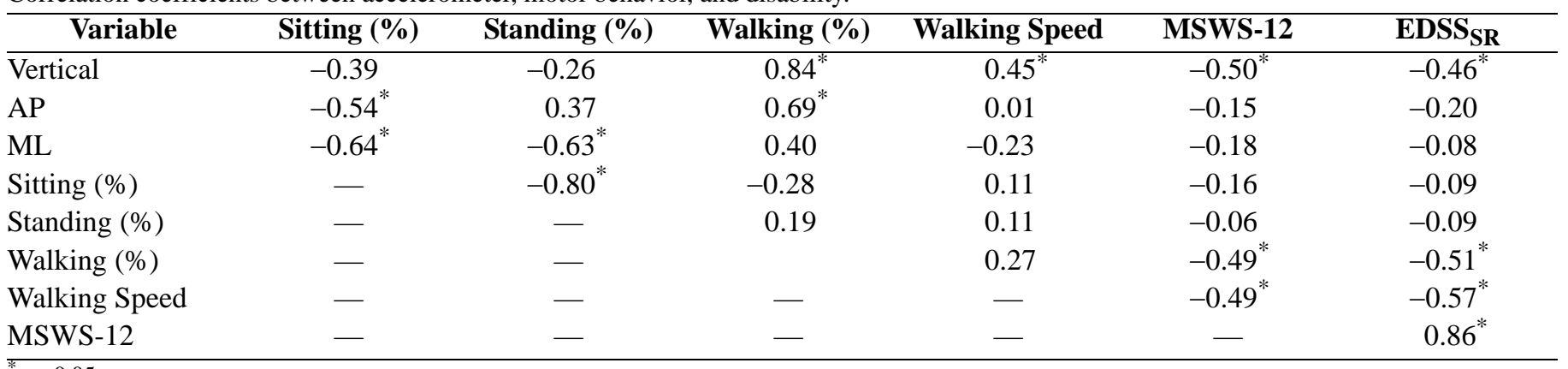

${ }^{*} p<0.05$.

$\mathrm{AP}=$ anterior-posterior axis of GT3X accelerometer, EDSS $_{\mathrm{SR}}=$ self-report Expanded Disability Status Scale, ML = mediolateral axis of GT3X accelerometer, MSWS-12 = Multiple Sclerosis Walking Scale-12, Vertical = vertical axis of GT3X accelerometer. 
walking speed [7] and that accelerometer data collected over a $7 \mathrm{~d}$ period are related to gait kinematics [8]. Taking this into consideration, the results from the present study further suggest that accelerometry is an objective marker of community walking in MS because counts/hour along the vertical axis were associated with community-based ambulation captured by the IDEEA system.

Despite the novelty of the present findings, this investigation had some limitations. One of the limitations was that the results are dependent on the algorithm implemented by the IDEEA system to determine walking behavior. It is possible that implementation of a different algorithm to detect walking in the acceleration profiles of the IDEEA system could change the association between the amount and quality of walking in MS and the output of the ActiGraph accelerometer. Additionally, data collection was limited to a single day of testing, excluding the examination of day to day variations. Lastly, given that the sample had on average a relatively low level of disability (median EDSS of 3.0), the current observations may not apply to those with greater disability. Although this is a limitation, it is important to note that 41 percent of the current sample used an assistive device during walking and that the current observations are likely to extend to those with greater impairment. Further work is necessary to examine this possibility.

\section{CONCLUSIONS}

The novel findings of this investigation are that the vertical signal from a commercially available, threedimensional, waist-worn accelerometer is related to the amount and quality of walking in a real-world environment in persons with MS. Combined with recent research on accelerometry and walking impairment, the current results indicate that accelerometry provides an objective marker of walking impairments that occur within the community among persons with MS. Future work is needed to determine whether accelerometry is sensitive to changes in gait as a function of disease, rehabilitation, pharmaceutical treatment, and/or disability progression.

\section{ACKNOWLEDGMENTS}

\section{Author Contributions:}

Study concept and design: J. J. Sosnoff, R. W. Motl.

Acquisition of data: M. K. Boes, M. J. Socie.
Analysis and interpretation of data: J. J. Sosnoff, B. M. Sandroff, M. K. Boes, M. J. Socie, R. W. Motl.

Drafting of manuscript: J. J. Sosnoff, R. W. Motl.

Critical revision of manuscript for important intellectual content: J. J. Sosnoff, B. M. Sandroff, M. K. Boes, M. J. Socie, R. W. Motl. Statistical analysis: J. J. Sosnoff, R. W. Motl.

Administrative, technical, or material support: J. J. Sosnoff, R. W. Motl, B. M. Sandroff, M. K. Boes, M. J. Socie.

Study supervision: J. J. Sosnoff.

Financial Disclosures: The authors have declared that no competing interests exist.

Funding/Support: This material was unfunded at the time of manuscript preparation.

Institutional Review: Participants were informed of the experimental procedures and signed a consent form approved by a university institutional review board.

Participant Follow-Up: The authors do not plan to inform participants of the publication of this study.

\section{REFERENCES}

1. Larocca NG. Impact of walking impairment in multiple sclerosis: perspectives of patients and care partners. Patient. 2011;4(3):189-201. [PMID:21766914] http://dx.doi.org/10.2165/11591150-000000000-00000

2. Scheinberg L, Holland N, Larocca N, Laitin P, Bennett A, Hall H. Multiple sclerosis; earning a living. N Y State J Med. 1980;80(9):1395-1400. [PMID:6938807]

3. Bethoux F, Bennett SE. Evaluating walking in patients with multiple sclerosis. Int J MS Care. 2011;13(1):4-14. http://dx.doi.org/10.7224/1537-2073-13.1.4

4. Sosnoff JJ, Goldman MD, Motl RW. Real-life walking impairment in multiple sclerosis: preliminary comparison of four methods for processing accelerometry data. Mult Scler. 2010;16(7):868-77. [PMID:20534642] http://dx.doi.org/10.1177/1352458510373111

5. Weikert M, Motl RW, Suh Y, McAuley E, Wynn D. Accelerometry in persons with multiple sclerosis: measurement of physical activity or walking mobility? J Neurol Sci. 2010;290(1-2):6-11. [PMID:20060544]

http://dx.doi.org/10.1016/j.jns.2009.12.021

6. Pearson OR, Busse ME, van Deursen RW, Wiles CM. Quantification of walking mobility in neurological disorders. QJM. 2004;97(8):463-75. [PMID:15256604] http://dx.doi.org/10.1093/qjmed/hch084

7. Motl RW, Sosnoff JJ, Dlugonski D, Suh Y, Goldman M. Does a waist-worn accelerometer capture intra- and interperson variation in walking behavior among persons with multiple sclerosis? Med Eng Phys. 2010;32(10):1224-28. [PMID:20875952] http://dx.doi.org/10.1016/j.medengphy.2010.08.015

8. Sosnoff JJ, Weikert M, Dlugonski D, Smith DC, Motl RW. Quantifying gait impairment in multiple sclerosis using GAITRite technology. Gait Posture. 2011;34(1):145-47. 


\section{[PMID:21531562]}

http://dx.doi.org/10.1016/j.gaitpost.2011.03.020

9. Weikert M, Dlugonski D, Balantrapu S, Motl RW. Most common types of physical activity self-selected by people with multiple sclerosis. Int J MS Care. 2011;13(1):16-20. http://dx.doi.org/10.7224/1537-2073-13.1.16

10. Poser CM. The diagnosis and management of multiple sclerosis. Acta Neurol Scand. 2005;112(3):199-201. [PMID:16097966] http://dx.doi.org/10.1111/j.1600-0404.2005.00450.x

11. Poser S. Symptomatology and diagnosis of multiple sclerosis. JAMA. 1982;248(9):1065. [PMID:7109196] http://dx.doi.org/10.1001/jama.1982.03330090037018

12. McDonald WI, Compston A, Edan G, Goodkin D, Hartung HP, Lublin FD, McFarland HF, Paty DW, Polman CH, Reingold SC, Sandberg-Wollheim M, Sibley W, Thompson A, van den Noort S, Weinshenker BY, Wolinsky JS. Recommended diagnostic criteria for multiple sclerosis: guidelines from the International Panel on the diagnosis of multiple sclerosis. Ann Neurol. 2001;50(1):121-27.

[PMID:11456302]

http://dx.doi.org/10.1002/ana.1032

13. Hohol MJ, Orav EJ, Weiner HL. Disease steps in multiple sclerosis: a simple approach to evaluate disease progression. Neurology. 1995;45(2):251-55. [PMID:7854521] http://dx.doi.org/10.1212/WNL.45.2.251

14. Hohol MJ, Orav EJ, Weiner HL. Disease steps in multiple sclerosis: a longitudinal study comparing disease steps and EDSS to evaluate disease progression. Mult Scler. 1999; 5(5):349-54. [PMID:10516779]

15. Hobart JC, Riazi A, Lamping DL, Fitzpatrick R, Thompson AJ. Measuring the impact of MS on walking ability: the 12-Item MS Walking Scale (MSWS-12). Neurology. 2003;60(1):31-36. [PMID:12525714]

http://dx.doi.org/10.1212/WNL.60.1.31

16. Mackey AH, Hewart P, Walt SE, Stott NS. The sensitivity and specificity of an activity monitor in detecting functional activities in young people with cerebral palsy. Arch Phys Med Rehabil. 2009;90(8):1396-1401.

[PMID:19651274]

http://dx.doi.org/10.1016/j.apmr.2009.01.029

17. Gorelick ML, Bizzini M, Maffiuletti NA, Munzinger JP, Munzinger U. Test-retest reliability of the IDEEA system in the quantification of step parameters during walking and stair climbing. Clin Physiol Funct Imaging. 2009;29(4): 271-76. [PMID:19302230]

http://dx.doi.org/10.1111/j.1475-097X.2009.00864.x

18. Maffiuletti NA, Gorelick M, Kramers-de Quervain I, Bizzini M, Munzinger JP, Tomasetti S, Stacoff A. Concurrent validity and intrasession reliability of the IDEEA accelerometry system for the quantification of spatiotemporal gait parameters. Gait Posture. 2008;27(1):160-63.
[PMID:17336070]

http://dx.doi.org/10.1016/j.gaitpost.2007.01.003

19. Huddleston J, Alaiti A, Goldvasser D, Scarborough D, Freiberg A, Rubash H, Malchau H, Harris W, Krebs D. Ambulatory measurement of knee motion and physical activity: preliminary evaluation of a smart activity monitor. J Neuroeng Rehabil. 2006;3:21. [PMID:16970818] http://dx.doi.org/10.1186/1743-0003-3-21

20. Gardner MJ, Barker JU, Briggs SM, Backus SI, Helfet DL, Lane JM, Lorich DG. An evaluation of accuracy and repeatability of a novel gait analysis device. Arch Orthop Trauma Surg. 2007;127(3):223-27. [PMID:17195932] http://dx.doi.org/10.1007/s00402-006-0279-2

21. Goldman MD, Marrie RA, Cohen JA. Evaluation of the six-minute walk in multiple sclerosis subjects and healthy controls. Mult Scler. 2008;14(3):383-90.

[PMID:17942508]

http://dx.doi.org/10.1177/1352458507082607

22. Kragt JJ, van der Linden FA, Nielsen JM, Uitdehaag BM, Polman CH. Clinical impact of $20 \%$ worsening on Timed 25-foot Walk and 9-hole Peg Test in multiple sclerosis. Mult Scler. 2006;12(5):594-98. [PMID:17086905] http://dx.doi.org/10.1177/1352458506070768

23. Hoogervorst EL, Kalkers NF, Uitdehaag BM, Polman CH. A study validating changes in the multiple sclerosis functional composite. Arch Neurol. 2002;59(1):113-16. [PMID:11790238] http://dx.doi.org/10.1001/archneur.59.1.113

24. Hobart J, Kalkers N, Barkhof F, Uitdehaag B, Polman C, Thompson A. Outcome measures for multiple sclerosis clinical trials: relative measurement precision of the Expanded Disability Status Scale and Multiple Sclerosis Functional Composite. Mult Scler. 2004;10(1):41-46.

[PMID:14760951] http://dx.doi.org/10.1191/1352458504ms983oa

Submitted for publication November 17, 2011. Accepted in revised form February 13, 2012.

This article and any supplementary material should be cited as follows:

Sosnoff JJ, Socie MJ, Boes MK, Sandroff BM, Motl RW. Does a waist-worn ActiGraph accelerometer quantify community ambulation in persons with multiple sclerosis? J Rehabil Res Dev. 2012;49(9):1405-10.

http://dx.doi.org/10.1682/JRRD.2011.11.0218

ResearcherID: Jacob J. Sosnoff, PhD: I-4429-2012

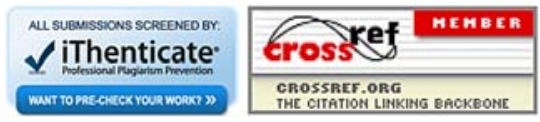


